\title{
INDUCTION OF NK CELLS AND INTERMEDIATE TCR CELLS WITH PROTECTIVE ABILITY FROM VIRAL INFECTIOUS DEATH, AT THE EARLY PHASE OF HERPES VIRUS INFECTION
}

\author{
Katsuhiko Hasegawa ${ }^{1}$, Kazuo Ohtsuka ${ }^{1}$, Fumio Shimizu ${ }^{3}$, Yasuyuki Kawachi' ${ }^{2}$, Mauro Nakayama ${ }^{2}$, \\ Kazunari Sato ${ }^{1}$, Satoshi Yamagiwa ${ }^{1}$, Katsuhiro Tomiyama ${ }^{2}$, Hitoshi Asakura ${ }^{1}$ and Toru Abo ${ }^{2,4}$ \\ ${ }^{1}$ Third Department of Internal Medicine and ${ }^{2}$ Department of Immunology, Niigata University School of Medicine, Niigata 951, \\ Japan, and ${ }^{3}$ Laboratory of Oral Medicine, National Institute of Dental Research, Bethesda, MD 20892, U.S.A.
}

\begin{abstract}
Extrathymic $\mathrm{T}$ cells can be easily distinguished from thymus-derived $\mathrm{T}$ cells, in terms of their expression levels of TCR (or CD3) and IL-2 receptor $\beta$-chain (IL-2R $\beta$ ). In this study, we examined how extrathymic T cells and thymus-derived $\mathrm{T}$ cells were activated in various organs during viral infection. When $\mathrm{C} 3 \mathrm{H} / \mathrm{He}$ mice were intraperitoneally inoculated with herpes simplex virus (HSV) of type $1-\mathrm{GC}^{+}$strain at a sublethal dose, $3 \times 10^{4} \mathrm{PFU} / \mathrm{mouse}$, the number of mononuclear cells (MNC) in the liver and spleen was stable but that of thymocytes decreased gradually up to 7 days after infection. However, a striking change of lymphocyte subsets was seen in the liver, namely, an increase in the proportion of NK cells $\left(\mathrm{CD} 3^{-} \mathrm{IL}-2 \mathrm{R} \beta^{+}\right)$and extrathymic T cells $\left(\mathrm{CD} 3\right.$-intermediate $\left.{ }^{+} \mathrm{IL}-2 \mathrm{R} \beta^{+}\right)$on day 3 and 7. Reflecting this change, $\gamma \delta \mathrm{T}$ cells and double-negative $\mathrm{CD} 4^{-} 8^{-} \mathrm{T}$ cells, which are components of extrathymic T cells, became elevated on day 3. Pre-elimination of NK cells and intermediate CD3 cells by an in vivo injection of anti-IL-2R $\beta$ mAb made mice susceptible to death by infection. All irradiated (6Gy) mice also became susceptible to death, but $1 \times$ $10^{7}$ adoptive transfer of liver MNC, but not of splenic MNC, obtained from HSV-immunized mice was effective in preventing death $(50 \%)$. The experiment in which mice were treated with anti-asialoGM $\mathrm{GM}_{1}$ antibody showed that NK cells were much more important for early phase protection than were intermediate CD3 cells. MNC were also isolated from the lung, the major target organ, in HSV-infected mice. Intermediate CD3 cells and granulocytes increased in this organ. These results suggest that a serial induction of primitive lymphocytes such as NK cells and extrathymic T cells may be crucial for early protection from viral infection.
\end{abstract}

Host defense system against viral infections has been intensively investigated, and several humoral factors (e.g., interferon, immunoglobulins, and complements) $(5,14,24)$ and cellular components

\footnotetext{
${ }^{4}$ To whom correspondence should be addressed Abbreviations: ADCC, antibody-dependent cell-mediated cytotoxicity; CTL, cytotoxic T cells; IL-2R $\beta$, IL-2 receptor $\beta$-chain; HSV-1, herpes simplex virus type-1; $\mathrm{PFU}$, plaque forming unit; MNC, mononuclear cells; $\mathrm{DN}$, double-negative
}

(e.g., macrophages, $\mathrm{K}$ cells, and $\mathrm{T}$ cells) $(4,6,13$, 20-22) are known to be associated with the resistance to viral diseases. Effector cells in cell-mediated immunity for viral infections are known to be $\mathrm{K}$ cells for antibody-dependent cell-mediated cytotoxicity (ADCC) (6), NK cells (4), and cytotoxic T cells (CTL) of thymic origin $(6,9,20$, 21). However, there is no information yet as to how intermediate TCR cells of extrathymic origin are responsible for viral infections.

In a series of recent studies $(1,7,15,16,19,23$, 
26), a unique population of $T$ cells were found to exist in the liver and other immune organs in mice. Since these hepatic $\mathrm{T}$ cells have intermediate levels of TCR (or CD3) (i.e., intermediate TCR cells) and constitutively express the IL- 2 recepter $\beta$-chain (IL-2R $\beta$ ), they are easily distinguished from thymus-derived $\mathrm{T}$ cells which carry high levels of TCR (i.e., high TCR cells) and lack the expression of IL-2R $\beta$. In a subsequent study (18), we demonstrated that intermediate TCR cells as well as NK cells play crucial roles in the defence of an intracellular pathogen, Listeria monocytogenes, possibly due to their autoreactivity to the infected selfcells.

Similarly, virus is an intracellular pathogen and many virally infected cells are thought to escape from recognition by usual $\mathrm{T}$ cells of thymic origin (i.e., foreign antigen recognition). In this regard, attention was focused on how intermediate TCR cells in various immune organs are modulated and are responsible for resistance during viral infection. When mice were infected with herpes simplex virus type-1 (HSV-1), a prominent increase in the proportion and the number of intermediate TCR cells was induced at the early phase of infection. Interestingly, the order of lymphocyte subset induction was NK cells $\rightarrow$ intermediate TCR cells of extrathymic origin $\rightarrow$ high TCR cells of thymic origin. Taken together with the data from a functional study, it was revealed that intermediate TCR cells as well as NK cells may intimately contribute to the defence mechanisms involved in the early phase of viral infection.

\section{MATERIALS AND METHODS}

\section{Mice}

Female $\mathrm{C} 3 \mathrm{H} / \mathrm{He}$ mice were bred and maintained in the animal facility of Niigata University School of Medicine. They were fed under specific pathogenfree conditions. All mice were used at 5 to 10 weeks of age.

In vivo Elimination of $N K$ Cells or Intermediate TCR Cells in Mice by the Treatment with Anti-AsialoGM, Antibody or Anti-IL-2R $m$ mAb

As shown previously $(25,27)$, a single i.p. administration of anti-asialoGM $M_{1}$ antibody $(0.2 \mathrm{mg} /$ mouse) eliminated NK cells, whereas anti-IL-2R $\beta$ $\mathrm{mAb}$ eliminated both NK cells and intermediate TCR cells. These methods were applied in this study. Such mice were used on day 3 (the maximum effect was emerged) after treatments.

\section{Cell Preparation}

Hepatic mononuclear cells (MNC) were prepared as previously described (7). Briefly, mice anesthetized with ether were killed by total exsanguination from the incised axillary artery and vein. The liver was removed, cut into small pieces with scissors, pressed through 200-gauge stainless steel mesh, and suspended in Eagle's MEM containing $5 \mathrm{mM}$ HEPES (Nissui Pharmaceutical, Tokyo, Japan) and 2\% heat-inactivated newborn calf serum (NCS). After being washed once with the medium, the cell pellet was resuspended in $30 \mathrm{ml}$ of the medium. MNC were isolated from parenchymal hepatocytes, the nuclei of hepatocytes, and Kupffer cells by the Ficoll-Isopaque gradient (1.090) centrifugation method. The MNC preparation isolated by this method contained less than $4 \%$ Kupffer cells.

Splenocytes and thymocytes were obtained by pressing pieces of the spleen and thymus, respectively, through 200-gauge stainless steel mesh and suspended in the medium. The splenocyte suspension was depleted of red blood cells with $0.83 \%$ ammonium chloride-Tris buffer. To obtain lung MNC, the lung was cut into small pieces. These pieces were incubated in MEM medium supplemented with $0.05 \%$ collagenase (WAKO, Osaka, Japan) and $0.01 \%$ trypsin inhibitor (Sigma, St. Louis, MO, U.S.A.), with stirring for $30 \mathrm{~min}$ at $37^{\circ} \mathrm{C}$. These pieces and supernatant were passed through stainless 200-gauge steel mesh. The cells were then washed with the MEM medium with $2 \%$ NCS, and fractionated by $35 \%$ Percoll (containing $100 \mathrm{U} / \mathrm{ml}$ heparin) gradient centrifugation for 15 $\min$ at $2,000 \mathrm{rpm}$ (3). The pellet was resuspended in the lysing buffer solution for depleting RBC and was then washed twice in the medium.

\section{Adoptive Transfer of Liver MNC or Splenic $M N C$}

Adoptive transfer of liver MNC or splenic MNC was carried out into 6Gy-irradiated mice. Liver $\mathrm{MNC}$ or splenic MNC were obtained from mice recovered from $\mathrm{HSV}$-infection. In some experiments, mice were pretreated with anti-asialoGM antibody to eliminate NK cells from HSV-infected mice. MNC $\left(1 \times 10^{7}\right)$ were intravenously injected immediately after irradiation. 


\section{Immunofluorescence Tests}

Phenotypes of the cells were identified by using $\mathrm{mAbs}$ in conjunction with single- or two-color immunofluorescene tests (16). The mAbs used here were FITC- or biotin-conjugated reagents of hamster anti-CD3 (145-2C11) (PharMingen, San Diego, CA, U.S.A.), anti-CD8 (53.6.7; Becton Dickinson, Mountain View, CA, U.S.A.), anti-CD4 (GK1.5), anti-TCR $\alpha \beta$ (H57-597), anti-TCR $\gamma \delta$ (GL3) and anti-IL-2R $\beta$ (TM- $\beta 1$ ) mAbs (PharMingen). FITCconjugated anti-granulocyte (Gr-1) mAb (PharMingen) and biotin-conjugated anti-granulocytemacrophage (CD11b, Mac-1) mAb (Caltag Lab., San Francisco, CA, U.S.A.) were also used. Biotinconjugated reagent was developed with PE-conjugated streptavidin (Becton Dickinson). The fluorescence-positive cells were analyzed by FACScan with Lysis II software (Becton Dickinson).

\section{Viral Infection}

HSV type $1-\mathrm{GC}^{+}$strain was used as a model of viral infection (8). Mice were inoculated intraperitoneally with $3 \times 10^{4}$ plaque forming unit (PFU) of HSV-1 and then sacrificed at various days after infection. Mice became free from infection on day 7 to 10 . If mice were treated with anti-IL-2R $\beta$ $\mathrm{mAb}$ or irradiation $(6 \mathrm{~Gy})$, they became susceptible to the death by viral injection.

\section{Cytotoxicity Assay}

Cytotoxicity was examined by a ${ }^{51} \mathrm{Cr}$-specific release assay with an incubation time of $4 \mathrm{~h}$, as previously described (10). YAC-1 target cells labelled with sodium chromate (Amersham International, Arlington Heights, IL, U.S.A.) were used, whereas effector cells were either hepatic MNC or splenic MNC isolated from normal or treated mice. Percent cytotoxicity was produced at the indicated ratios of target to effector cells. Triplicate cultures were performed to produce the mean and one SD.

\section{Histology}

A regular hematoxylin-eosin (H-E) staining was applied by using the tissues with formalin fixation.

\section{Statistical Analysis}

Statistical significance was analyzed by using Student's $t$-test.

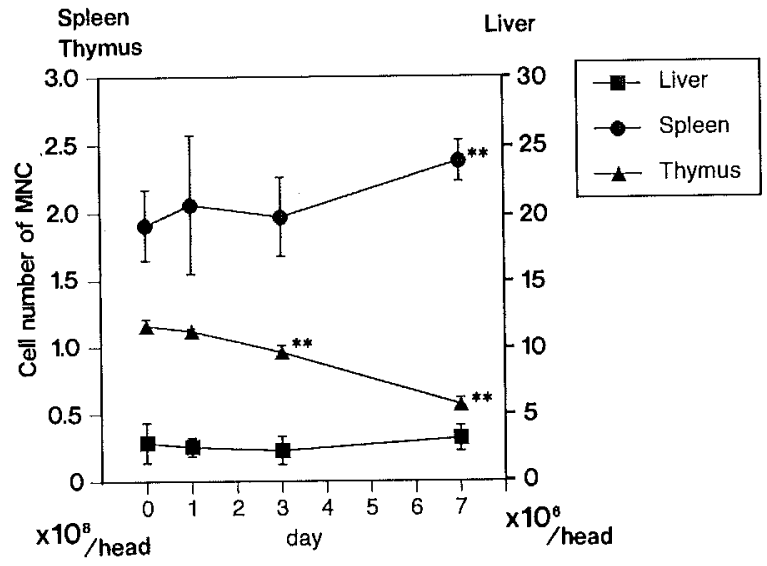

Fig. 1 Time-kinetics of the number of MNC yielded by the liver, spleen, and thymus in mice with HSVinjection. $\mathrm{C} 3 \mathrm{H} / \mathrm{He}$ mice aged 8 weeks were inoculated with $3 \times 10^{4} \mathrm{PFU}$ of HSV-1. Mice were sacrificed at the indicated days and the numbers of MNC determined. The mean and one SD were produced from the data of six mice. The number of thymocytes decreased gradually, but the number of splenic MNC increased at the late stage. $* * P<0.01$

\section{RESULTS}

Time-Kinetics of the Number of MNC Yielded by the Liver, Spleen, and Thymus after HSV-Infection

Mice were inoculated with a sublethal dose of HSV- $1\left(3 \times 10^{4} \mathrm{PFU} / \mathrm{mouse}\right)$ and the numbers of $\mathrm{MNC}$ in the liver, spleen and thymus determined (Fig. 1). The number of liver MNC remained constant while the number of thymocytes decreased gradually. On day 7 , thymic atrophy was approximately $50 \%$. The number of splenic MNC only increased on day 7 .

Increase in the Proportion of NK Cells and Intermediate CD3 Cells in the Liver after HSV-Infection

We then investigated how lymphocyte subsets varied in these organs after HSV-infection (Fig. 2). To identify simultaneously various lymphocyte subsets, two-color staining for $\mathrm{CD} 3$ and $\mathrm{IL}-2 \mathrm{R} \beta$ was carried out at the indicated days. As shown in the liver and spleen of control mice, this staining identified NK cells (CD3-IL-2R $\beta^{+}$), intermediate CD3 cells $\left(\mathrm{CD} 3\right.$-intermediate ${ }^{+} \mathrm{IL}-2 \mathrm{R} \beta^{+}$) and high $\mathrm{CD} 3$ cells (CD3-high ${ }^{+} \mathrm{IL}-2 \mathrm{R} \beta^{-}$). NK cells and intermediate CD3 cells were more abundant in the liver than in the spleen. Thymocytes comprised $\mathrm{CD}^{-}$, 


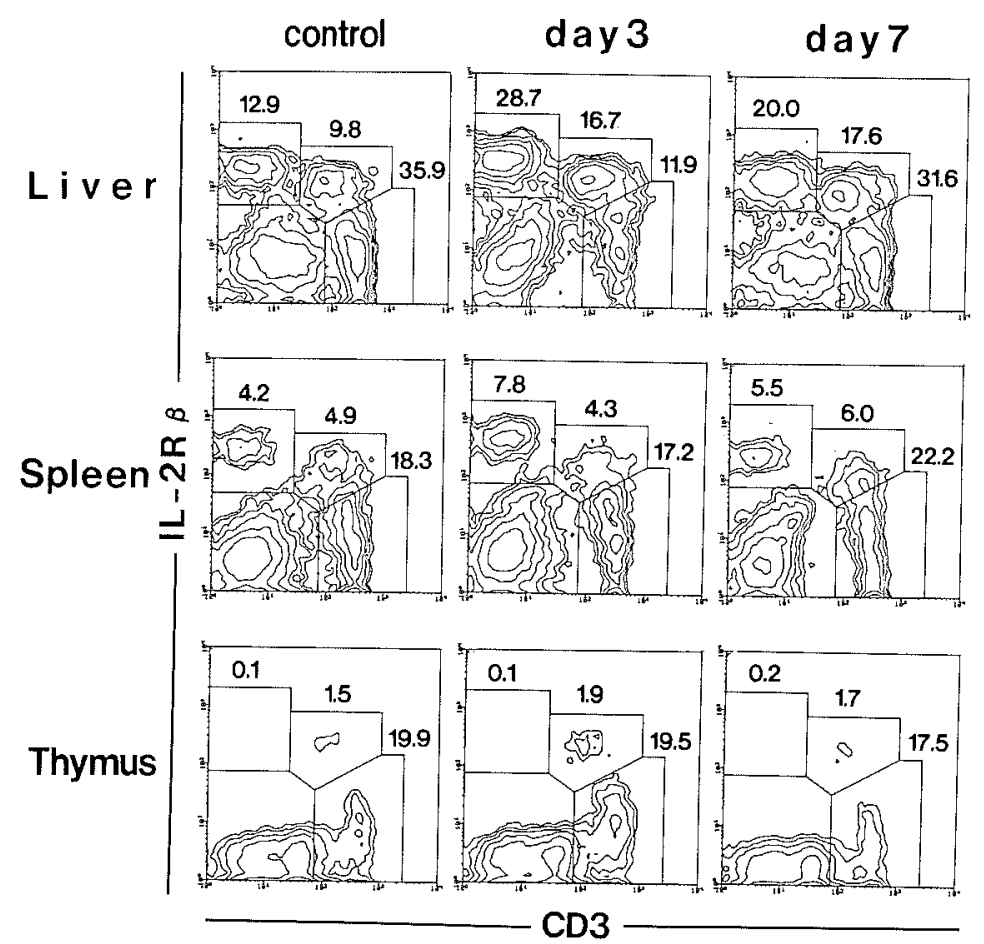

Fig. 2 Increase in the proportions of NK cells and intermediate CD3 cells in the liver of mice with HSV-injection. Two-color staining for $\mathrm{CD} 3$ and IL-2R $\beta$ was carried out to identify NK cells $\left(\mathrm{CD}^{-} \mathrm{IL}-2 \mathrm{R} \beta^{+}\right)$, intermediate $\mathrm{CD} 3$ cells $\left(\mathrm{CD} 3\right.$-intermediate ${ }^{+} \mathrm{IL}-$ $2 \mathrm{R} \beta^{+}$), and high CD3-cells (CD3-high $\left.{ }^{+} \mathrm{IL}-2 \mathrm{R} \beta^{-}\right)$. Numbers in the figure indicate the percentages of fluorescence-positive cells in corresponding areas. Representative results from three experiments are depicted. On day 3 and day 7 after injection, a prominent increase in the proportion of NK cells and intermediate CD3 cells was demonstrated.

CD3-low $^{+}$and CD3-high ${ }^{+}$cells, all of which lacked the expression of IL-2R $\beta$. The most striking change after HSV-infection was an increase in the proportions of NK cells and intermediate CD3 cells in the liver. This was true on day 3 and 7 after infection. High CD3 cells tended to decrease on day 3 in the liver. Other changes in the spleen and thymus were minimal.

To confirm the increase in the proportion of NK cells and intermediate CD3 cells in the liver, repeated experiments $(n=6)$ were performed. The data on the liver and spleen are depicted (Fig. 3). It was revealed that NK cells increased significantly on day 3 in the liver while intermediate CD3 cells did so on day 7 . The variation pattern was almost the same in the spleen. In other words, NK cells first expanded and intermediate CD3 cells subsequently expanded. On day 3 , high CD3 cells tended to decrease and then to return to a normal level in both organs.

\section{Further Phenotypic Characterization of Lymphocyte Subsets}

To determine how other surface phenotypes varied during HSV-infection, two-color staining for $\operatorname{TCR} \alpha \beta$ and TCR $\gamma \delta$ in MNC obtained from the liver, spleen, and thymus was carried out (Fig. 4A). In control mice, the major T-cell subsets were $\operatorname{TCR} \alpha \beta^{+}$in all tested organs. However, a small, but significant proportion of $\mathrm{TCR} \gamma \delta^{+}$cells were present in the liver. After HSV-infection, such TCR $\gamma \delta^{+}$cells increased in the liver on day 3 and 7. Since all $\mathrm{TCR} \gamma \delta^{+}$cells belong to the intermediate CD3 population (26), this phenomenon reflected the increase of $\mathrm{CD} 3$ cells in the liver after HSV-infection.

Two-color staining for CD3 and a mixture of 

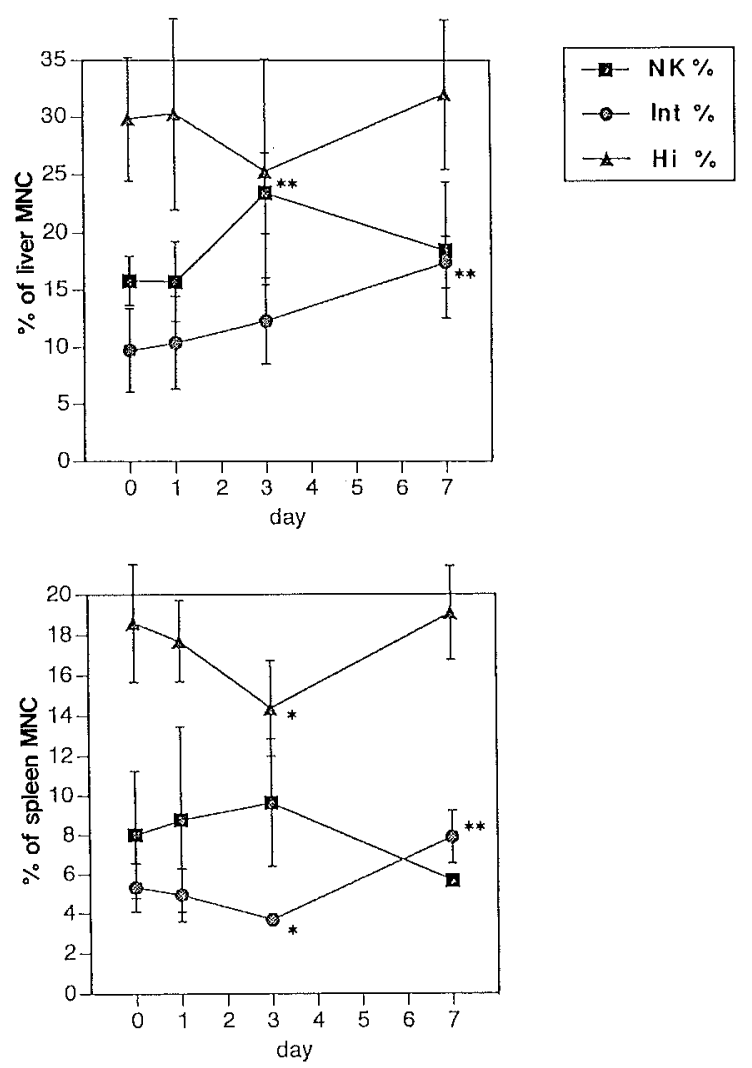

Fig. 3 Time-kinetics of the proportions of NK cells, intermediate CD3 cells, and high CD3 cells in the liver and spleen of mice with HSV-injection. The identification of each lymphocyte population was done as shown in Fig. 2. The mean and one SD were produced from the data of six mice. The proportion of NK cells increased on day 3 while that of intermediate CD3 cells increased on day 7 in the liver. $* P<0.05$, $* * P<0.01$

CD4 and CD8 was then carried out (Fig. 4B). Reflecting the increase in the proportion of intermediate CD3 cells, the proportion of double-negative (DN) $\mathrm{CD} 4^{-} 8^{-}$cells increased in the liver on day 3. DN cells are always confined to a population of intermediate CD3 cells (26). A rare population of $\mathrm{CD}^{-} \mathrm{CD}^{+}$(determined from the staining intensity) cells emerged considerably in the liver on day 3. They might have been NK cells that acquired CD8 antigens. The other staining patterns in other organs remained unchanged.

Two-color staining for CD4 and CD8 showed no significant change, except in the liver (Fig. 4C). The proportion of $\mathrm{CD}^{+}$cells decreased in the liver on day 3 , possibly due to the decrease of high CD3 cells.

\section{NK Functional Activity}

In this experiment, NK activity of MNC was examined in the liver and spleen before and after (on day 7) HSV-infection (Fig. 5). As shown previously (10), liver MNC have the highest NK activity among $\mathrm{MNC}$ in various immune organs and $80 \%$ of such activity were found to be mediated by NK cells while $20 \%$ were by intermediate CD3 cells. As expected, liver MNC had higher NK activity against YAC-1 target than splenic MNC, and such activity in both organs was further elevated after infection. This result from the functional study corresponds well to that from the phenotypic study.

\section{Elimination of NK Cells and Intermediate CD3 Cells Made Mice Susceptible to Death by Infection}

Since NK cells and intermediate CD3 cells constitutively express IL-2R $\beta$, it was investigated whether in vivo injections of anti-IL-2R $\beta$ mAb (TM- $\beta 1$ ) were able to eliminate these populations (Fig. 6A). On day 3 after injection, all NK cells and intermediate $\mathrm{CD} 3$ cells were eliminated from both the liver and the spleen. Detailed characterization showed us that a single i.p. injection of antiIL-2R $\beta$ mAb $(0.5 \mathrm{mg} / \mathrm{ml})$ maintained the above conditions from day 1 to 5 after injection.

Three days and 1 day before HSV-inoculation, mice were injected with anti-IL-2R $\beta \mathrm{mAb}$ and the survival rate of these mice was examined (Fig. 6B). Control mice were intraperitoneally injected with PBS alone. Eighty percent of the IL-2R $\beta$ negative mice died within a week after infection.

\section{Liver MNC Obtained from Mice Which Had Recovered from HSV-Infection Contained Cells Protective against Infection}

Liver MNC always contain the greatest abundance of NK cells and intermediate CD3 cells as compared with MNC in various organs (7). Using adoptive transfer experiments, we investigated whether such populations actually mediated a protective function against $\mathrm{HSV}$-infection (Fig. 7A). In this experiment, mice were $6 \mathrm{~Gy}$ irradiated and liver MNC or splenic MNC $\left(1 \times 10^{7} /\right.$ mouse $)$ were then intravenously injected. In an initial experiment, we used liver MNC and splenic MNC isolated from non-immunized mice. However, the number of cells transferred was not sufficient to pre- 


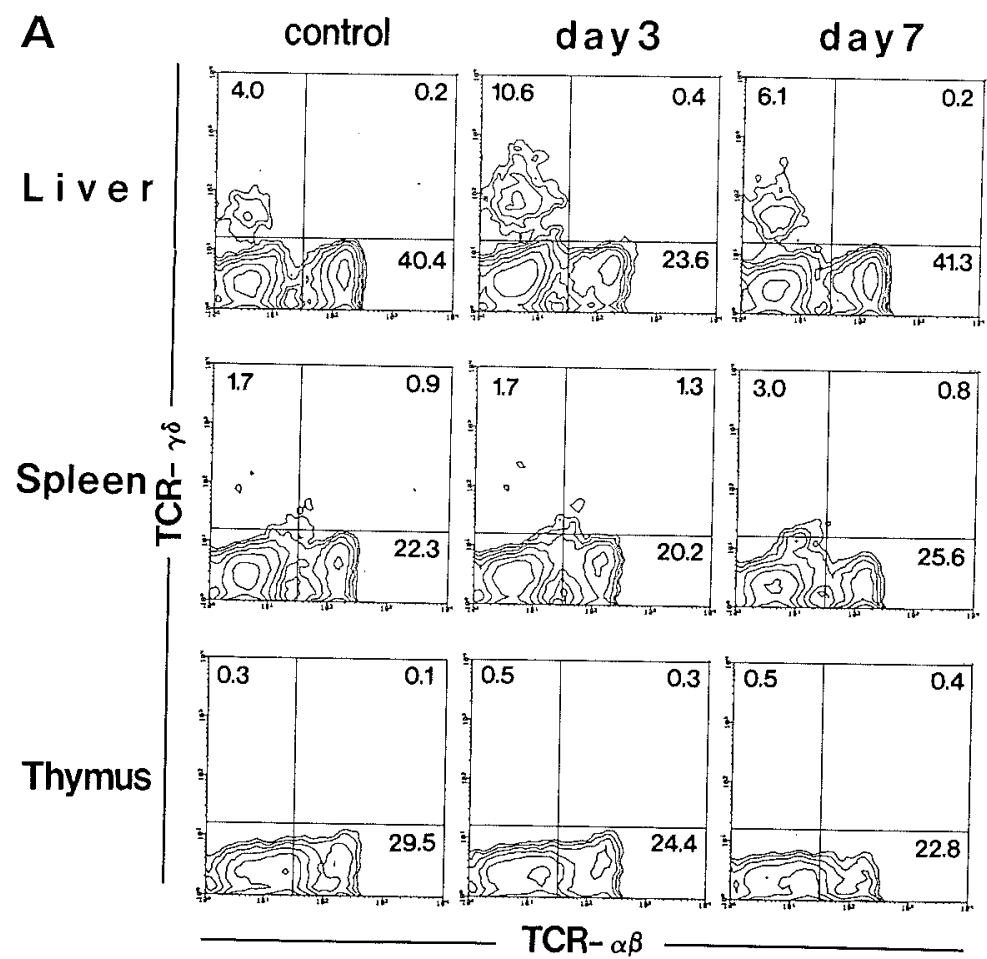

Fig. $4 \mathrm{~A}$

Fig. 4 Increase in the proportion of $\gamma \delta$ T cells and $\mathrm{DN} \mathrm{CD4} 4^{-} 8^{-} \mathrm{T}$ cells in the liver of mice with HSV-infection. A: Two-color staining for TCR $-\alpha \beta$ and TCR- $\gamma \delta$. B: Two-color staining for CD3 and a mixture of CD4 and CD8. C: Two-color staining for CD4 and CD8. Numbers in the figure represent the percentage of fluorescence-positive cells. Representative results from three experiments are depicted. The proportion of $\gamma \delta \mathrm{T}$ cells and $\mathrm{DN} \mathrm{CD4} 4^{-} 8^{-}$cells, which are components of intermediate CD3 cells, increased in parallel with the increase of intermediate $\mathrm{CD} 3$ cells.

vent the death of mice by infection (data not shown). We then isolated MNC from mice which had recovered from HSV-infection. Although all irradiated mice died of the infection within a week, more than $50 \%$ of the mice which had received liver MNC were able to survive. This result was very striking when compared with mice which had received splenic MNC. None of these mice survived. It is possible that hepatic $\mathrm{T}$ cells, possibly intermediate CD3 cells, in the liver were immunized by the prior infection and acted as effector cells protecting against HSV-infection.

To determine which lymphocytes (NK cells and intermediate CD3 cells) are most important for the protection, we injected the NK-depleted fractions (treated with anti-asialoGM $M_{1}$ antibody) of either liver MNC or splenic MNC obtained from HSVimmunized mice (Fig. 7B). In this mouse, protec- tion against $\mathrm{HSV}$-induced death was virtually eliminated. This result indicated that the initial defense was performed mainly by NK cells. However, some protective ability of liver MNC was still seen after the treatment with anti-asialoGM ${ }_{1}$ antibody, because some mice exhibited prolongation of survival rate. In conjunction with the earlier data from HSV-immunized mice, intermediate CD3 cells have the ability to act as a second defense or anamnestic defense against HSV-infection.

\section{Consolidation of the Lung by HSV-Infection}

We then produced several histologic H-E preparations in HSV-infected mice to know how mice fell victims of infection (Fig. 8). One of the most prominent changes was seen in the lung. The lung displayed the consolidation of the tissue and some 

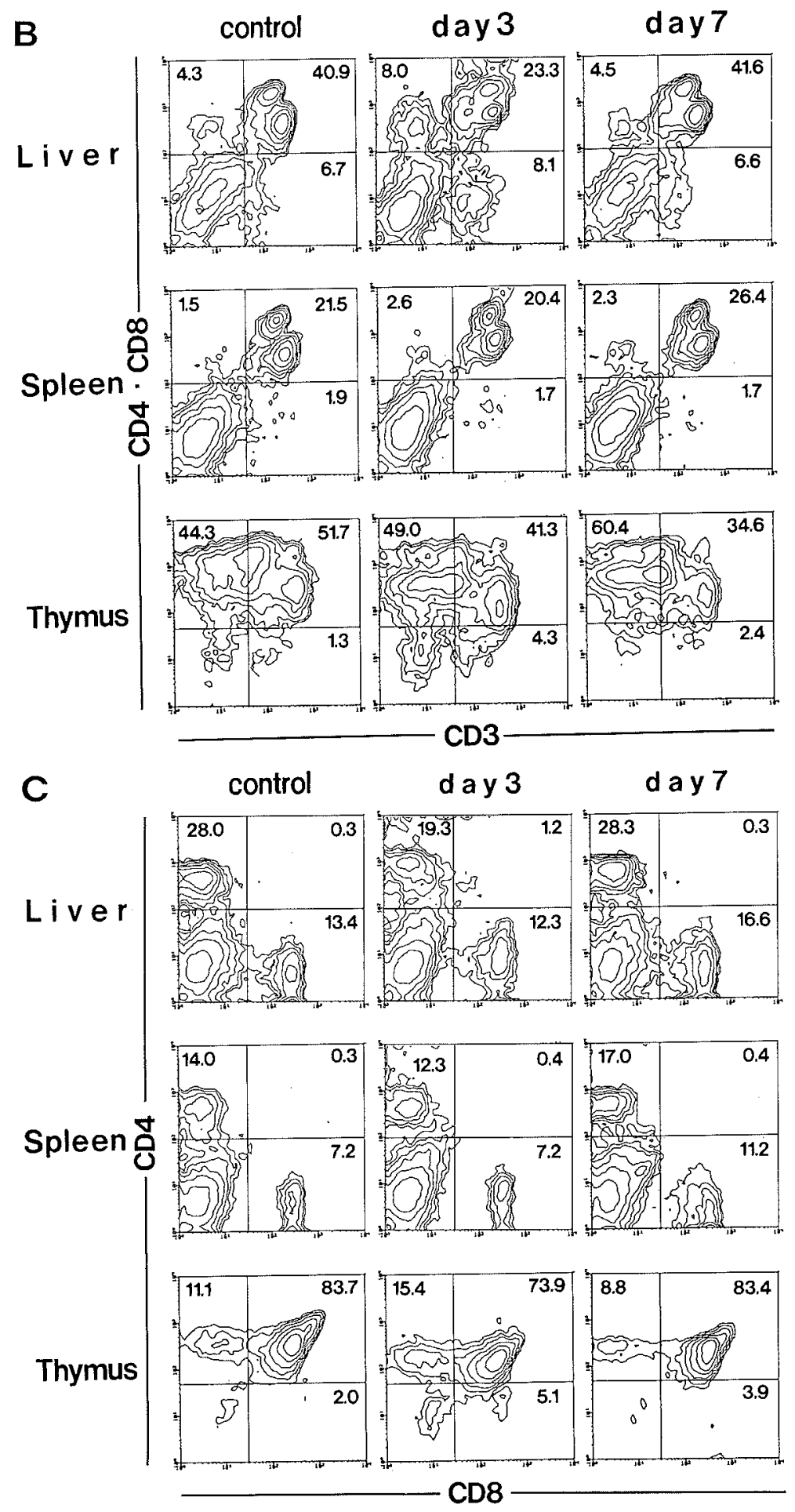

Fig. 4, B and C 

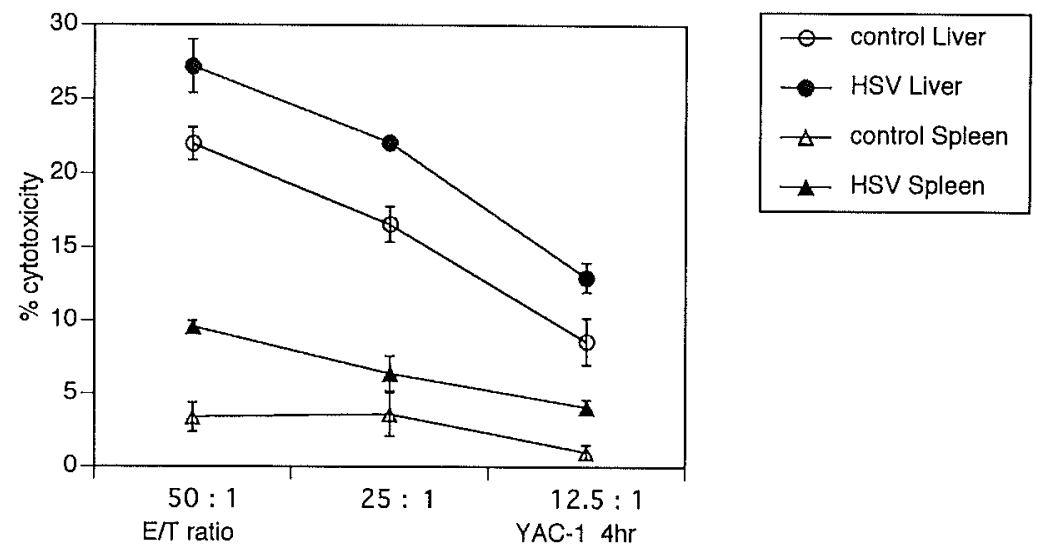

Fig. 5 Increase in the cytotoxic activity of $\mathrm{MNC}$ in the liver and spleen of mice with $\mathrm{HSV}$-infection. $\mathrm{NK}$ function was determined by ${ }^{51} \mathrm{Cr}$-release assay using YAC-1 target cells. Four-hour incubation was performed at the indicated effector-to-target ratios. A prominent increase in the cytotoxic activity was induced both in the liver and spleen of mice with HSV-infection.

lymphoid cells are infiltrating.

To determine what types of lymphoid cells infiltrated the lung, MNC were isolated from the lung in HSV-infected mice. Two-color stainings were performed in various combinations as indicated (Fig. 9). In control mice, MNC in the lung comprised mainly NK cells and IL-2R $\beta^{-}$high CD3 cells. However, after infection (day 5) IL-2R $\beta^{+}$ intermediate $\mathrm{CD} 3$ cells became predominant. The most striking change in this organ was an increase in $\mathrm{Gr}-1^{+} \mathrm{Mac}-1^{+}$granulocytes. Since the absolute number of lung MNC increased 10-times greater after the infection, the increase in intermediate CD3 cells and granulocytes was substantial. Granulocytes might be responsible for the destruction of lung tissues. A similar result was produced on day 3 after infection (data not shown).

\section{DISCUSSION}

In the present study, we demonstrated that NK cells and intermediate TCR cells are important for the protection from HSV infectious death, especially at the early phase of infection. Thus, a phenotypic study revealed that, at the early phase of HSV-infection, NK cells and intermediate TCR cells were serially induced. Furthermore, the elimination of NK cells by anti-asialoGM $\mathrm{M}_{1}$ antibody and the simultaneous elimination of NK cells and intermediate TCR cells by anti-IL-2R $\beta$ mAb caused mice to become susceptible to death at the early phase of infection. Concerning the properties ascribed to NK cells and intermediate TCR cells in previous studies, they may be more primitive lymphocytes than thymus-derived $\mathrm{T}$ cells in phylogenetic development $(2,11,12,17,28)$. It is therefore conceivable that primitive lymphocytes may be much more important for the protection against viral death in the early phase of infection. Since it is apparent that thymus-derived $\mathrm{T}$ cells require sufficient time to acquire immunity (i.e., clonal expansion), the above primitive lymphocytes play a crucial role in protection before the acquisition of immunity. This notion seems to be reasonable, because NK cells and intermediate TCR cells constitutively express IL-2R $\beta$ (but not $\mathrm{IL}-2 \mathrm{R} \alpha$ ) and respond quickly to many stimuli, such as a superantigen, staphylococcal enterotoxin $\mathrm{B}$, and IL2 itself (26).

It is well known that CTL (i.e., thymus-derived $\mathrm{CD}^{+}$cells), NK cells and $\mathrm{K}$ cells are associated with protection against viral infection $(4,6,9,20$, $21)$. CTL might recognize viral antigens in the context of self-MHC molecules on antigen-presenting cells such as dendritic cells and macrophages. However, it is presumed that the induction of CTL requires several days for the acquisition of immunity after infection because of clonal expansion. On the other hand, $\mathrm{NK}$ and $\mathrm{K}$ cells are known to be another type of effector cells for resistance against viruses $(4,6)$. The most well-established mechanism is ADCC by $\mathrm{K}$ cells. Even in this case, 


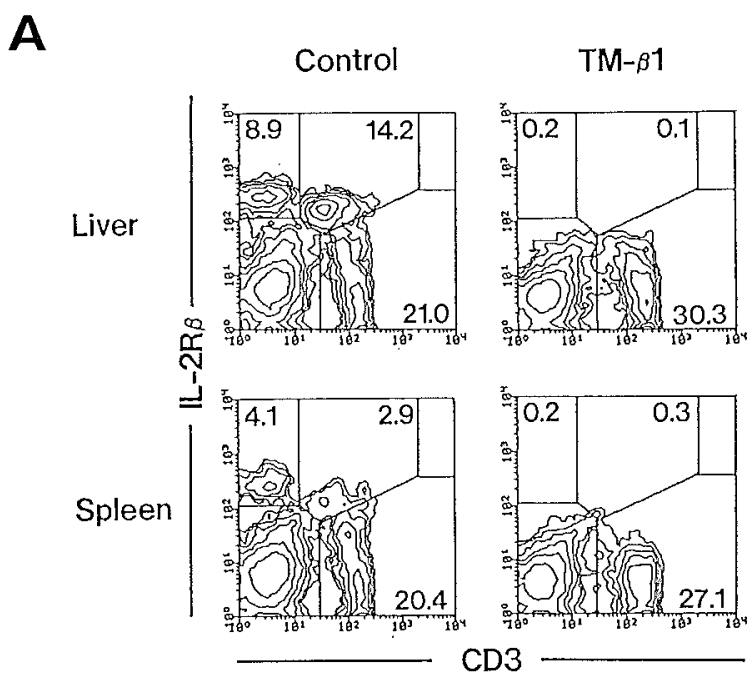

B

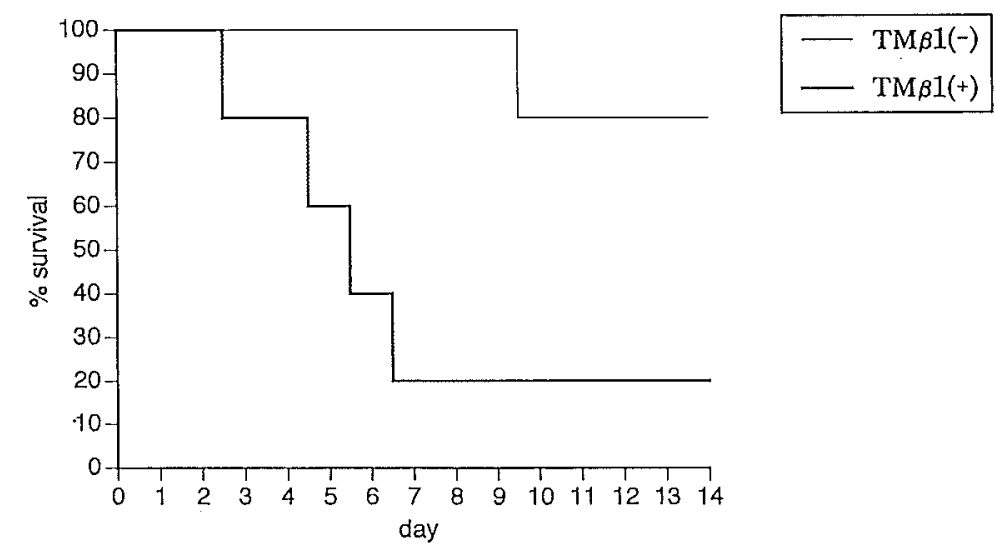

Fig. 6 Elimination of NK cells and intermediate CD3 cells by antiIL-2R $\beta$ mAb causes mice to become susceptible to death by HSVinfection. A: Elimination of NK cells and intermediate CD3 cells by the injection of anti-IL-2R $\beta(\mathrm{TM}-\beta 1) \mathrm{mAb}$. B: Mice in which NK cells and intermediate CD3 cells were eliminated were killed by HSV infection at a high frequency. Ten mice from each group were used.

since the antibody against viral antigens is essential, sufficient time for immunization of B cells is required. We propose herein that NK cells and intermediate TCR cells are effector cells for the initial protection against viral death. If this is the case, it is speculated that NK cells and intermediate TCR cells might recognize the infected self-cells as abnormal self rather than foreign, viral antigens.

There is a question of how CTL or thymusderived $\mathrm{T}$ cells are associated with viral protection.
From the present results, it is speculated that thymus-derived $\mathrm{T}$ cells (i.e., high TCR cells in this study) are associated with the final stage of infection. Thus, the number and proportion of high TCR cells rather decreased in the early phase of HSVinfection. However, on day 7 after infection, at the time when mice escaped from viral infection, the number of high TCR cells increased. It is conceivable that disseminated viruses from virally infected self-cells which are disrupted by NK cells or intermediate TCR cells, are finally processed by high 

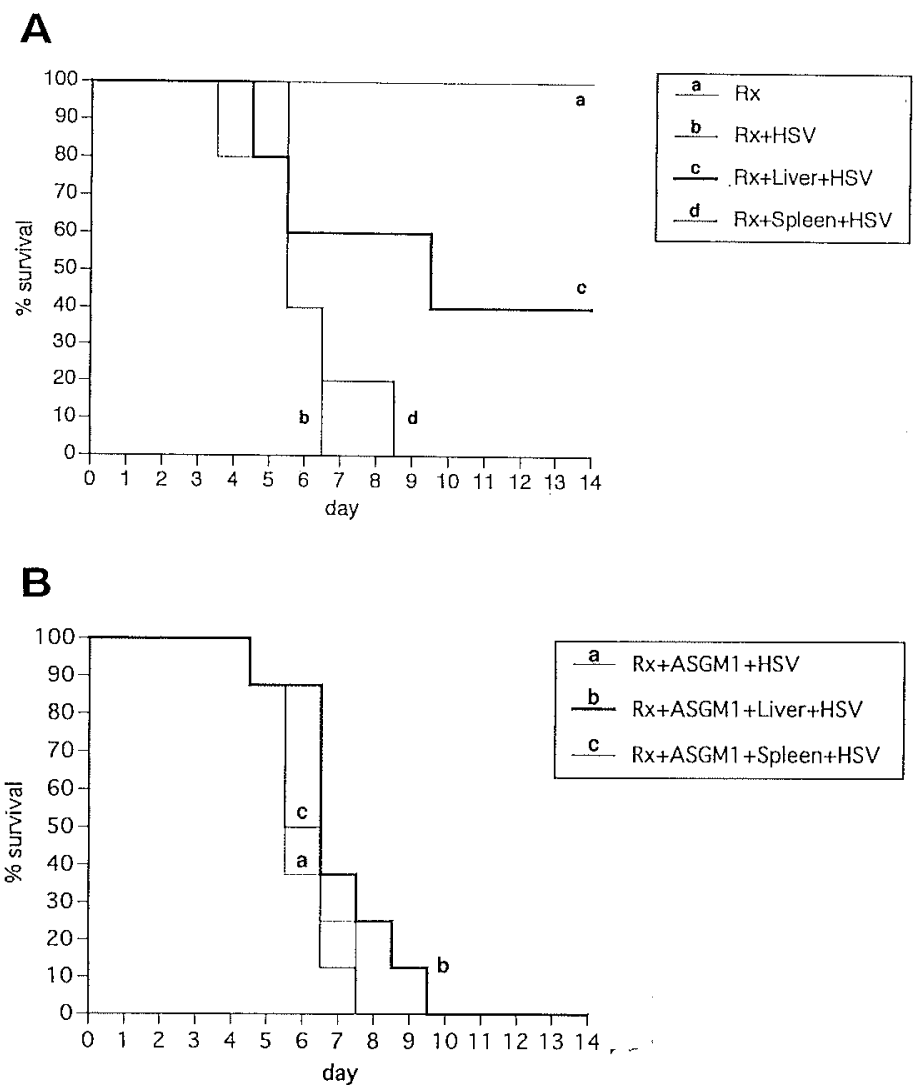

Fig. 7 Protective effects of NK cells and intermediate CD3 cells against HSV-infection. A: Reconstitution of liver MNC into irradiated mice causes to become slightly resistant to viral infection. B: Reconstitution of NK-depleted liver MNC into irradiated mice causes mice to become slightly resistant to viral infection. To determine how lymphocyte subsets are responsible for the resistance to HSV-infection, irradiated mice were reconstituted with $1 \times 10^{7} \mathrm{MNC}$ from various sources. Anti-asialo$\mathrm{GM}_{1}$ antibody was used to eliminate NK cells.

TCR cells in an antigen-specific manner.

In the present study, we applied two-color staining for $\mathrm{CD} 3$ and IL-2R $\beta$ to identify NK cells, intermediate CD3 cells, and high TCR cells. This method is very useful for simultaneously identifying various lymphocyte subsets $(17,27)$. Since intermediate $\mathrm{CD} 3$ cells have intermediate levels of TCR (or CD3) and constitutively express IL$2 \mathrm{R} \beta$, they are easily distinguishable from $\mathrm{IL}-2 \mathrm{R} \beta^{-}$ high TCR (or CD3) cells. In contrast to the ability of high TCR cells to acquire the high affinity IL2R (IL-2R $\alpha^{+} \beta^{+}$), intermediate TCR cells hardly express IL-2R $\alpha$, even after activation. Namely, intermediate TCR cells express only up to the intermediate affinity IL-2R (IL-2R $\alpha^{-} \beta^{+}$). This also explains why intermediate TCR cells as well as NK cells show earlier activation to viral infection than do high TCR cells. This may also reflect their order of phylogenetic development. Indeed, intermediate TCR cells have unique primitive properties such as high levels of $\gamma \delta$ T cells and of DN $\mathrm{CD}^{-} 8^{-}$cells. HSV-infection also induces lymphocyte subsets carrying these properties, especially in the early phase of infection.

The most rapid response of lymphocyte subsets was seen in NK cells on day 3 after HSV-infection. This phenotypic identification was confirmed by an NK functional study using YAC-1 target cells. As shown previously (10), MNC in the liver, as compared with those in various other organs, were able 


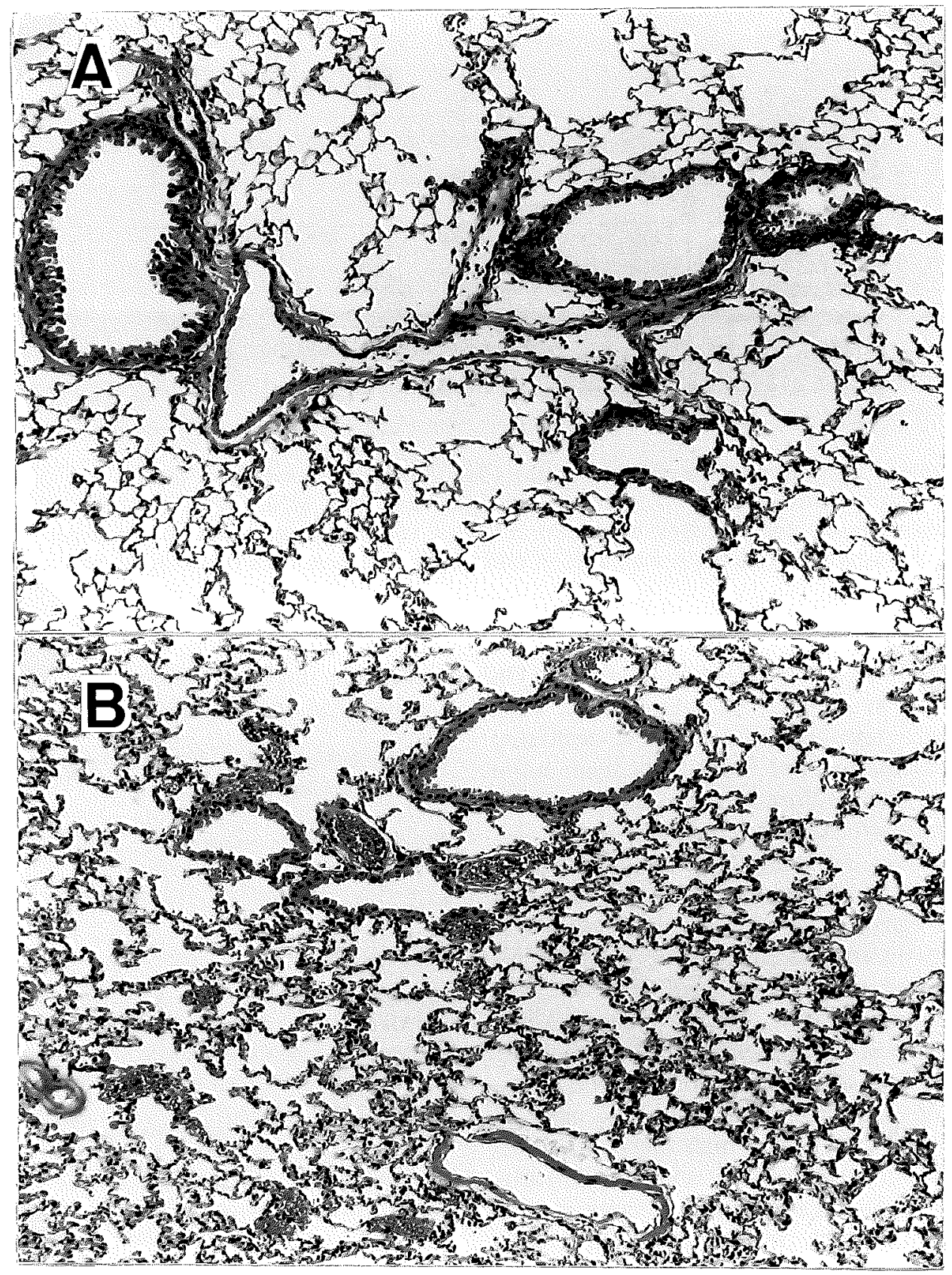

Fig. 8 Pneumonitis in mice induced by HSV-infection $(\times 100)$. A: Lung of control mice. B: Lung of HSV-infected mice. Mice were sacrificed on day 7 after HSVinfection. Infected mice showed the tissue consolidation in the lung, manifesting some lymphocyte infiltration.

to mediate the most potent activity of NK function. Approximately $80 \%$ of this NK function were mediated by NK cells themselves, whereas $20 \%$ of the NK function were by intermediate TCR cells. Although intermediate TCR cells showed a lower cytotoxicity against the NK target, they had a potent cytotoxic activity against syngeneic hepatoma or lymphoma in the presence of anti-CD3 (or TCR) $\mathrm{mAb}$ (our unpublished observation). If virally infected self-cells are recognized by NK cells, 


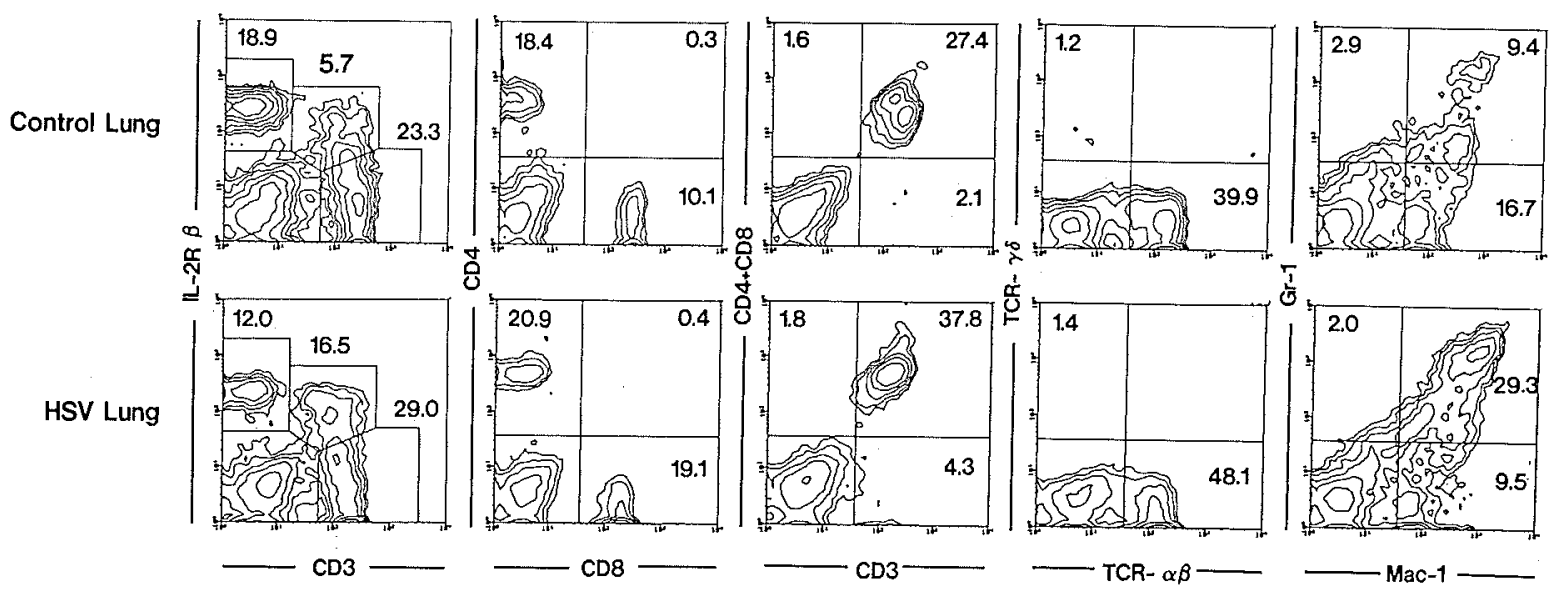

Fig. 9 Increase in the proportion of intermediate CD3 cells and granulocytes in the lung of HSV-infected mice. Mice were sacrificed on day 7 after HSV-infection and lung MNC were isolated by the collagenasetreated method. Two-color stainings were performed in various combinations as indicated in the figure. Numbers in the figure indicate the percentages of fluorescence-positive cells in corresponding areas.

such recognition is non-MHC restricted (17). On the other hand, in the case of intermediate TCR cells, they recognize them in an MHC-restricted manner. Since intermediate TCR cells seem more effective when obtained from immunized mice with virus, they may have some memory responses.

We applied two antibodies to eliminate specific lymphocyte subsets. Although anti-IL-2R $\beta \mathrm{mAb}$ is known to be effective for the elimination of NK cells (25), we showed herein that this $\mathrm{mAb}$ eliminated in vivo not only IL-2R $\beta^{+}$NK cells but also IL-2R $\beta^{+}$intermediate TCR cells. Namely, this is a very useful method for simultaneously eliminating primitive lymphocytes. On the other hand, antiasialoGM $\mathrm{G}_{1}$ antibody eliminates only NK cells in vivo. The experiments in which these methods were applied, indicated that NK cells are the earliest effector cells for viral infection without a prior immunization but that intermediate TCR cells seem to be associated with a subsequent second defense at an early phase of infection. In case of the lung, the target organ, the increase in granulocytes as well as intermediate CD3 cells was prominent. These granulocytes might be responsible for the tissue destruction, since they are known to produce free radicals and active oxygens after activation.

Finally, many investigators to date have searched for only a limited lymphocyte subset for the effector cells of viral protection. However, a serial induction of NK cells $\rightarrow$ extrathymic T cells $\rightarrow$ thymus-derived $\mathrm{T}$ cells suggests that all these cells have important effector functions, depending on the stage of viral infection.

We thank Mrs Kyona Kimura for her help in preparing the manuscript.

Received 10 November 1995; and accepted 30 November 1995

\section{REFERENCES}

1. Abo T., Oteki T., Seki S., Koyamada N., Yoshikal Y., Matsuda T., Rikishi H. and Kumagai K. (1991) The appearance of $\mathrm{T}$ cells bearing self-reactive $\mathrm{T}$ cell receptor in the livers of mice injected with bacteria. J. Exp. Med. 174, $417-424$

2. Arai K., Iiai T., Nakayama M., Hasegawa K., Sato K., Ohtsuka K., Watanabe H., Hanyu T., Takahashi H. E. and ABo T. (1995) Adhesion molecules on intermediate TCR cells. I. Unique expression of adhesion molecules, CD $44^{+} \mathrm{L}_{\text {-selectin }}^{-}$, on intermediate TCR cells in the liver and the modulation of their adhesion by hyaluronic acid. Immunology 84, 64-71

3. Goossens P. L., Jouin H., Marchal G. and Milon G. (1990) Isolation and flow cytometric analysis for the free lymphomyeloid cells present in murine liver. J. Immunol. Methods 132, 137-144

4. Habu S., Akamatsu K., Tamaoki N. and Okumura K. (1984) In vivo significance of NK cell on resistance against virus (HSV-1) infections in mice. J. Immunol. 133, 27432747

5. Hendricks R. L., Tumpey T. M. and Finnegan A. (1992) IFN- $\gamma$ and IL-2 are protective in the skin but pathologic in the corneas of HSV-1-infected mice. J. Immunol. 149, $3023-3028$

6. Heron I., Moller-Larsen A. and Berg K. (1977) Effector cell involved in cell-mediated cytotoxicity to cells infected 
with herpes simplex virus type 1. Infect. Immun, 16, 48-53

7. Iiai T., Watanabe H., Seki S., Sugiura K., Hirokawa K., Utsuyama M., Takahashi-Iwanaga H., Iwanaga T, OHTEKI T. and ABo T. (1992) Ontogeny and development of extrathymic $\mathrm{T}$ cells in mouse liver. Immunology 77, 556-563

8. Irie H., Harada Y., Yoshihashi H., Kimura T., Kojima M., Kataoka M., Saito M., Sugawara Y. and Mori W. (1989) Spread of herpes simplex virus type-1 (Miyama ${ }^{+} \mathrm{GC}$ strain) to the central nervous system after intraperitoneal inoculation: the role of the myenteric plexus of the gut. Arch. Virol. 105, 247-257

9. Johnson R. M., Lancki D. W., Sperling A. I., Dick R. F., Spear P. G., Fitch F. W. and Bluestone J. A. (1992) A murine $\mathrm{CD}^{-}, \mathrm{CD}^{-} \mathrm{T}$ cell receptor- $\gamma \delta$ T lymphocyte clone specific for herpes simplex virus glycoprotein I. J. Immunol. 148, 983-988

10. Kawachi Y., Iiai T., Moroda T., Watanabe T., Haga M., Watanabe H., Hatakeyama K. and Abo T. (1994) Profound suppression of the differentiation and functions of intermediate TCR cells in the liver of mice with liver injury induced by carbon tetrachloride. Biomedical Res. 15, 325336

11. Kimura M., Hanawa H., Watanabe H., Ogawa M. and Aвo T. (1995) Synchronous expansion of intermediate TCR cells in the liver and uterus during pregnancy. Cell. Immmol. 162, 16-25

12. Kimura M., Watanabe H., Ohtsuka K., Iiai T., Tsuchida M., SAto S. and Aвo T. (1993) Radioresistance of intermediate TCR cells and their localization in the body of mice revealed by irradiation. Microbiol. Immuntol. 37, 641652

13. Koff W. C., Showalter S. D., Seniff D. A. and Hampar B. (1983) Lysis of herpesvirus-infected cells by macrophages activated with free or liposome-encapsulated lymphokine produced by a murine $\mathrm{T}$ cell hybridoma. Infect. Immin. 42, 1067-1072

14. Master J. C. and Rouse B. T. (1991) The mouse model and understanding immunity to herpes simplex virus. Rev. Infect. Diseases 13, S935-S945

15. Ohteki T., Seki S., Abo T. and Kumagai K. (1990) Liver is a possible site for the proliferation of abnormal $\mathrm{CD}^{+} 4^{-} 8^{-}$double-negative lymphocytes in autoimmune MRL-lpr/lpr mice. J. Exp. Med. 172, 7-12

16. Ohtsuka K., Hasegawa K., Sato K., Arai K., Watanabe H., Asakura H. and ABo T. (1994) A similar expression pattern of adhesion molecules between intermediate TCR cells in the liver and intraepithelial lymphocytes in the intestine. Microbiol. Immunol. 38, 677-683

17. Ohtsuka K., Iiai T., Watanabe H., Tanaka T., Miyasaka M., Sato K., Asakura H. and Abo T. (1994) Similarities and differences between extrathymic $\mathrm{T}$ cells residing in mouse liver and intestine. Cell. Immunol. 153, 52-66

18. Ohtsuka K., Sato K., Watanabe H., Kimura M., AsaKURA H. and Aво T. (1995) Unique order of the lymphocyte subset induction in the liver and intestine of mice during Listeria monocytogenes infection. Cell. Immunol. 161, $112-124$

19. Okuyama R., Abo T., Seki S., Ohteki T., Sugiura K., Kusumi A. and Kumagai K. (1992) Estrogen administration activates extrathymic $\mathrm{T}$ cell differentiation in the liver. $J$. Exp. Med. 175, 661-669

20. Rola-Pleszczynski M., Hurtado R. C., Woody J. N., Sell. K. W., Vincent M. M., Hensen S. A. and Bellanti J. A. (1975) Identification of the cell population involved in viral-specific cell-mediated cytotoxicity in man: evidence for T cells specificity. J. Inmunol. 115, 239-242

21. Rosenberg G. L., Farber P. A. and Notkins A. L. (1972) In vitro stimulation of sensitized lymphocytes by herpes simplex virus and vaccinia virus. Proc. Natl. Acad. Sci. USA 69, 756-760

22. Schlabach A. J., Martinez D., Field A. K. and Tytell A. A. (1979) Resistance of C58 mice to primary systemic herpes simplex virus infection; Macrophage dependence and T-cell independence. Infect. Immun. 26, 615-620

23. Seki S., Abo T., Ohteki T., Sugiura K. and Kumagai K. (1991) Unusual $\alpha \beta$-T cells expanded in autoimmune $l p r$ mice are probably a counterpart of normal $\mathrm{T}$ cells in the liver. J. Immunol. 147, 1214-1221

24. Sethi K. K. and Brandis H. (1978) Interferon enhances T cell mediated cytotoxicity of $\mathrm{H}-2$ compatible target cells infected with UV-inactivated herpes simplex virus. Arch. Virol. 57, 177-183

25. Tanaka T., Kitamura F., Nagasaka Y., Kuida K, Suwa H. and Mryasaka M. (1993) Selective long-term elimination of natural killer cells in vivo by an anti-interleukin 2 receptor $\beta$ chain monoclonal antibody in mice. J. Exp. Med. 178, 1103-1107

26. Watanabe H., Iiai T., Kimura M., Ohtsuka K., Tanaka T., Miyasaka M., Tsuchida M., Hanawa H. and Abo T. (1993) Characterization of intermediate TCR cells in the liver of mice with respect to their unique IL-2R expression. Cell. Immunol. 149, 331-342

27. Watanabe H., Ohtsuka K., Kimura M., Ikarashi Y., Ohmori K., Kusumi A., Ohteki T., Seki S. and Abo T. (1992) Details of an isolation method for hepatic lymphocytes in mice. J. Inmunol. Methods 146, 145-154

28. Watanabe H., Ohtsuka K., Obata Y., Iiai T., Kimura M., Takahashi T., Hirokawa K., Utsuyama M. and Abo T. (1993) Generalized expansion of extrathymic $T$ cells in various immune organs of TL-transgenic mice. Biomedical Res. 14, 273-288 